\title{
Validação da medida de proteína C-reativa de alta sensibilidade (PCR-as) por quimioluminescência para estimativa de risco cardiovascular em individuos ambulatoriais: análise comparativa com nefelometria
}

\author{
Validation of C-reactive protein measured by immunoluminometry for cardiovascular risk assessment in the \\ outpatient setting: comparative analysis with nephelometry
}

José Carlos C. Lima'; Agnaluce Moreira²; Daniela Lima³; Luis C. L. Correia ${ }^{4}$

Unitermos
Proteina C-reativa
Risco cardiovascular
Quimioluminescência
Nefelometria

resumo

Fundamento: A proteína C-reativa de alta sensibilidade (PCR-as) é um preditor de risco cardiovascular estabelecido no cenário de prevenção primária, de acordo com os métodos de enzyme linked immunosorbent assay (ELISA) e nefelometria. O método de quimioluminescência tem sensibilidade suficiente para discriminação de baixos níveis de PCR-as, com valor preditor estabelecido em síndromes coronarianas agudas. No entanto este método carece de validação em indivíduos ambulatoriais, cujos valores de PCR são significativamente menores que os de pacientes instáveis. Objetivo: Testar a hipótese de que o método de quimioluminescência possui acurácia adequada para mensuração de PCR-as e classificar indivíduos ambulatoriais de acordo com o risco cardiovascular. Métodos: A proteína C-reativa foi medida pelos métodos de quimioluminescência e nefelometria em 152 amostras séricas obtidas de diferentes indivíduos ambulatoriais. Considerando-se a nefelometria o padrão-ouro, a performance do método de quimioluminescência foi avaliada. Resultados: Observou-se forte associação linear entre os dois métodos, ilustrada pelos coeficientes de correlação $(r=0,99 ; p<0,001)$ e regressão $(\beta=0,94,95 \%$ C.I. $=0,92$ $-0,95, p<0,001)$. A diferença média entre os valores de cada método foi - 0,22 $\pm 0,4 \mathrm{mg} / \mathrm{l}$. Em 97\% dos indivíduos houve concordância entre os métodos quando à classificação em baixo risco (PCR-as < $1 \mathrm{mg} / \mathrm{l})$, risco intermediário (PCR-as $=1-3 \mathrm{mg} / \mathrm{l})$ ou alto risco cardiovascular (PCR-as $>3 \mathrm{mg} / \mathrm{l})(\mathrm{kappa}=$ $0,96 ; p<0,001)$. Conclusão: A medida de PCR-as por quimioluminescência representa uma alternativa ao método nefelométrico na avaliação de risco cardiovascular de indivíduos ambulatoriais.

\section{abstract}

Background: High-sensitivity c-reactive protein (hs-CRP) is an established risk predictor in primary prevention. Among available laboratory methods, enzyme linked immunosorbent assay (ELISA) and nephelometry are the most validated for this clinical application. Immunoluminometry is another high-sensitivity method of hs-CRP, with definitive prognostic value in acute coronary syndromes. However, it lacks validation for cardiovascular risk prediction in the outpatient setting, whose hs-CRP values are in a lower range in relation to unstable patients. Objective: In an outpatient setting, test the hypothesis that the immunoluminometric method has enough accuracy to measure hs-CRP and classify individuals according to cardiovascular risk. Method: C-reactive protein was measured by the methods of immunoluminometry and nephelometry in 152 serum samples obtained from different outpatient subjects. Taken nephelometry as a gold-standard, performance of the immunoluminometric method was evaluated. Results: There was a strong linear association between the two methods, according to the correlation coefficient $(r=0.996$; $p<0.001)$ and regression coefficient $(\beta=0.94,95 \% \mathrm{C} . \mathrm{I} .=0.92-0.95, p<0.001)$. The mean difference between the two methods was $-0.22 \pm 0.4 \mathrm{mg} / \mathrm{l}$. In $97 \%$ of the subjects, there was agreement between the methods in definition of low risk ( $h s-C R P<1 \mathrm{mg} / \mathrm{l}$ ), intermediate risk ( $\mathrm{hs}-\mathrm{CRP}=1-3 \mathrm{mg} / \mathrm{l}$ ) or high cardiovascular risk ( $\mathrm{hs}-\mathrm{CRP}>3 \mathrm{mg} / \mathrm{l}$ ) $-k a p p a=0.96 ; p<0.001$. Conclusion: The immunoluminometric method of $h s-C R P$ represents an alternative to nephelometry for the assessment of cardiovascular risk in an outpatient population. key words

C-reactive protein

Cardiovascular risk

Immunoluminometry

Nephelomerty

1. MD; médico patologista clínico; presidente do Laboratório de Patologia Clínica (LPC), Salvador-BA; diretor-médico dos laboratórios do Hospital Português e da Cardio Pulmonar Serviços Médicos. 2. Mestra em Imunoensaios; gestora técnica/qualidade do LPC.

3. MD; médica residente no Hospital Roberto Santos, Salvador-BA.

4. MD; Ph.D.; especialista em Cardiologia pela Sociedade Brasileira de Cardiologia (SBC); fellow de pesquisa em Cardiologia na Universidade de Johns Hopkins; doutor em Medicina e Saúde pela Universidade Federal da Bahia (UFBA). 


\section{Introdução}

De acordo com dados experimentais, o processo inflamatório está intimamente implicado na gênese, na progressão e na ruptura da placa aterosclerótica ${ }^{(2,13)}$. Em concordância, a proteína C-reativa sérica (PCR-as) é um marcador inflamatório validado como preditor de risco cardiovascular em indivíduos aparentemente saudáveis. Tal predição é independente da concentração plasmática de colesterol e da presença de outros fatores de risco para doença aterosclerótica ${ }^{(8)}$. Baseando-se no conjunto de trabalhos epidemiológicos a este respeito, a recente publicação da American Heart Association e do Center for Disease Control sugere que $3 \mathrm{mg} / \mathrm{l}$ sejam considerados o ponto de corte para definir indivíduos de alto risco cardiovascular de acordo com seu status inflamatório( ${ }^{(7)}$.

Considerando este ponto de corte, em prevenção primária, a estratificação de risco cardiovascular pela PCR-as requer um método de alta sensibilidade, capaz de discriminar baixas concentrações. Estudos epidemiológicos iniciais utilizaram enzyme linked immunosorbent assay (ELISA) para medida de PCR-as ${ }^{(5,9)}$. Porém, devido à complexidade de sua realização, este método é primariamente usado para pesquisa, não sendo ideal para medidas clínicas de rotina. Por este motivo, o método nefelométrico para medida de PCR-as, plenamente automatizado, foi desenvolvido ${ }^{(10)}$, validado para predição de risco ${ }^{(8)}$ e disponibilizado comercialmente. A despeito de sua praticidade, a logística para nefelometria não é disponível de maneira universal. Desta forma, a presença de métodos alternativos pode tornar a medida de PCR-as de alta sensibilidade mais exeqüível. Recentemente, as sensibilidades da turbidimetria e da quimioluminescência têm sido aprimoradas na discriminação de níveis plasmáticos suficientemente baixos para avaliar risco cardiovascular ${ }^{(12)}$. Tais métodos foram amplamente testados em pacientes com síndromes coronarianas agudas, porém carecem de validação em populações estáveis, típicas do cenário de prevenção primária.

No intuito de testar a hipótese de que o método quimioluminescente para dosagem de PCR-as se presta para a avaliação do risco cardiovascular na população geral, os resultados foram pareados com os do método nefelométrico aplicado às mesmas amostras séricas, sendo avaliados quanto à semelhança dos valores e à concordância na definição de risco.

\section{Método}

\section{Casuística}

As amostras séricas utilizadas no estudo foram obtidas de indivíduos consecutivamente encaminhados ao nosso laboratório, durante novembro de 2003, para medida de PCR-as por diversos motivos clínicos. Foram excluídos soros com resultado $>15 \mathrm{mg} / \mathrm{l}$, a fim de avaliar uma amostra característica do cenário de prevenção primária. Desta forma, a amostra de conveniência foi constituída de 152 indivíduos, predominantemente jovens (30 \pm 11 anos) e do sexo masculino $(n=110)$.

\section{Dosagens laboratoriais}

Cada indivíduo forneceu uma única amostra sérica, utilizada para medida de $\mathrm{PCR}$-as pelos métodos nefelométrico e quimioluminescente. Para análise de reprodutibilidade em baixas concentrações, um subgrupo de dez amostras aleatoriamente selecionadas sofreu diluição 1/10 com albumina bovina $60 \mathrm{~g} / \mathrm{l}$. Reagentes comercialmente disponíveis foram utilizados para as dosagens laboratoriais. Pelo método nefelométrico (Dade Behring Inc., Newark, DE, EUA), a aglutinação das partículas recobertas por anticorpos anti-PCR é mensurada pela intensidade da luz refletida, utilizando-se o equipamento $B N 100^{(10)}$. O método de quimioluminescência (Diagnostic Products Corporation, Los Angeles, CA, EUA) baseia-se na detecção da luz emitida pelo resultante da reação química entre a molécula de PCR-as e o substrato quimioluminescente 1,2 dioxetano. $O$ equipamento Immulite 1000 foi utilizado para tal medida ${ }^{(4)}$.

\section{Análise dos dados}

Para avaliar se as medidas de PCR-as obedeciam à distribuição normal, foi utilizado o teste de Kolmogorov-Smirnov. Tais medidas foram expressas por mediana, intervalo interquartil e amplitude. A presença de associação linear entre os dois métodos de PCR-as foi avaliada pelos coeficientes de regressão linear ( $\beta$ ) e de correlação não-paramétrico Spearman $(r)$, considerando o método nefelométrico a variável independente e o método quimioluminescente, a dependente. A concordância entre os métodos foi avaliada pela técnica de Bland-Altman, e a diferença entre os valores, expressa por média \pm desvio-padrão. De acordo com estudos epidemiológicos, a delimitação entre tercis de PCR-as se situa em torno dos seguintes pontos de corte: $<1 \mathrm{mg} / \mathrm{l}$, $1-3 \mathrm{mg} / \mathrm{l}$ e $>3 \mathrm{mg} / \mathrm{l}$. Esses três grupos definem pacientes de baixo, médio e alto risco cardiovascular, respectivamente ${ }^{(7)}$. 
Considerando estes limites, a concordância entre os dois métodos na definição de risco pela PCR-as foi avaliada pelo teste kappa. Além disso, a proporção de amostras cujas diferenças entre os métodos foram $>0,5 \mathrm{mg} / \mathrm{l}$ foi relatada como forma de expressar o número de pacientes com diferença expressiva. A análise de Bland-Altman foi repetida no subgrupo com PCR-as entre 0 e $4 \mathrm{mg} / \mathrm{l}$, intervalo em que acontece a distinção de risco pela PCR-as. Para cálculo da reprodutibilidade do método de quimioluminescência, duas medidas repetidas no subgrupo das dez amostras diluídas foram realizadas, calculando-se o coeficiente de variabilidade. Significância estatística foi definida como $p<0,05$ e o programa SPSS versão 10.0 (Chicago, IL, USA) foi usado para o cálculo destes valores.

\section{Resultados}

\section{Descrição dos valores de PCR-as}

De acordo com ambos os métodos laboratoriais, as distribuições dos valores de PCR-as não obedeceram à distribuição normal $(p<0,001)$, com desvio para a direita. As medidas do método nefelométrico variaram de 0,103 a 13,2 $\mathrm{mg} / \mathrm{l}$, mediana $2 \mathrm{mg} / \mathrm{l}$, intervalo interquartil 1,1 a $4,8 \mathrm{mg} / \mathrm{l}$. O método quimioluminescente apresentou medidas entre 0,104 e 13,4mg/l, mediana 2,1 mg/l e intervalo interquartil 1,1 a $4,6 \mathrm{mg} / \mathrm{l}$.

\section{Associação linear entre nefelometria e quimioluminescência}

A correlação dos valores pareados de PCR-as mostrou forte associação linear entre os métodos nefelométrico e quimioluminescente, demonstrada pelos coeficientes de correlação $(r=0,99 ; p<0,001)$ e regressão $(\beta=0,94 ; 95 \%$ I.C. $=0,92-0,95 ; p<0,001)$ (Figura 1).

\section{Concordância entre os valores de nefelometria e quimioluminescência}

A despeito da forte associação linear, a análise de BlandAltman mostra que os valores dos dois métodos diferem, com tendência a subestimativa pelo método quimioluminescente (Figura 2). A diferença média entre os valores dos dois métodos (quimioluminescência e nefelometria) foi de $0,22 \pm 0,4 \mathrm{mg} / \mathrm{l}$. Na minoria das amostras $(n=28$, $18 \%$ ), esta diferença superou $0,5 \mathrm{mg} / \mathrm{l}$. A diferença é mais acentuada $(0,48 \pm 0,56 \mathrm{mg} / \mathrm{l})$ quando se analisam altos valores de PCR-as (> $4 \mathrm{mg} / \mathrm{l}, n=51$ ). Por outro lado, a análise dos 101 indivíduos com valores de PCR-as entre 0 e $4 \mathrm{mg} / \mathrm{l}$ (intervalo de discriminação de risco) mostra clara semelhança entre os dois métodos $(0,08 \pm 0,15 \mathrm{mg} / \mathrm{l})$ (Figura 3). Neste grupo apenas $2 \%$ das amostras apresentaram diferença $>0,5 \mathrm{mg} / \mathrm{l}$.

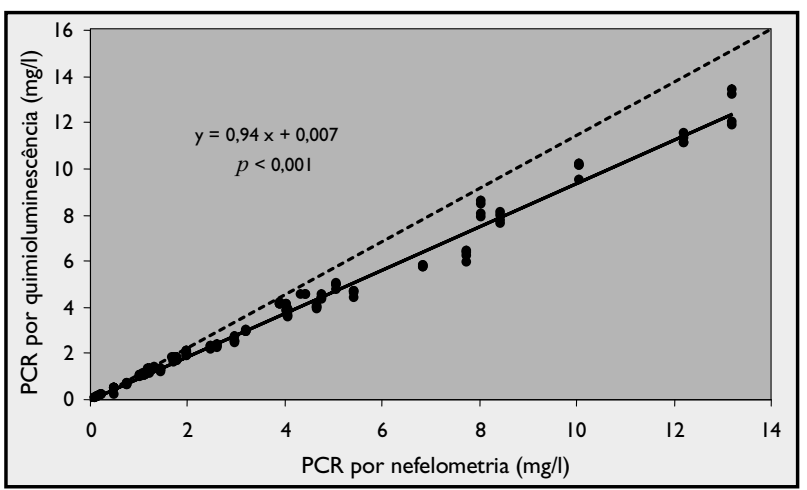

Figura 1 - Análise de regressão linear entre as medidas de proteína C-reativa de alta sensibilidade (PCR-as) realizadas pelos métodos nefelométrico e quimioluminescente

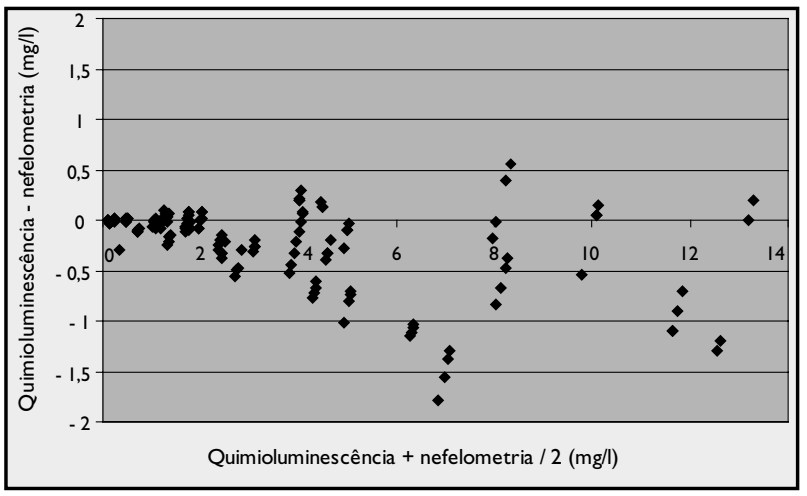

Figura 2 - Análise de Bland-Altman entre as medidas de proteína C-reativa (PCR-as) realizadas pelos métodos nefelométrico e quimioluminescente

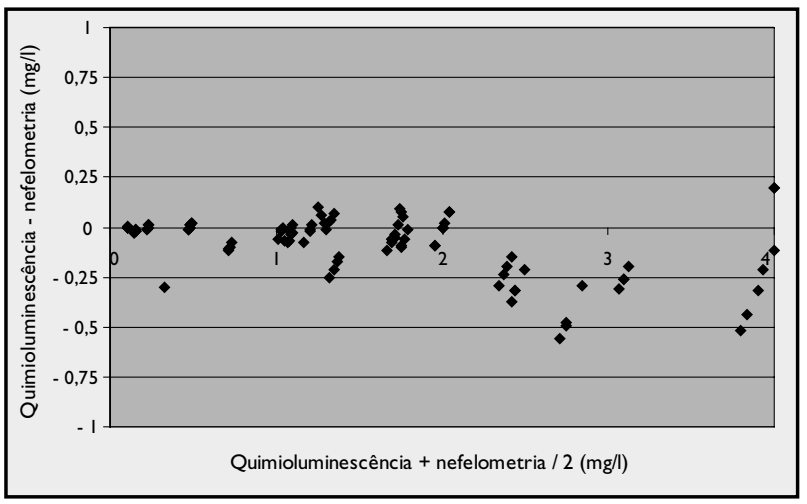

Figura 3 - Análise de Bland-Altman entre as medidas de proteína C-reativa (PCR-as) realizadas pelos métodos nefelométrico e quimioluminescente em amostras dentro do limite de maior importância para discriminação de risco cardiovascular $(0-4 m g / l)$ 


\section{Concordância na definição de risco cardiovascular por nefelometria e quimioluminescência}

De acordo com o método nefelométrico, $18 \%$ dos pacientes são classificados como de baixo risco pela PCR-as $(<1 \mathrm{mg} / \mathrm{l}), 41 \%$ como de risco intermediário $(1-3 \mathrm{mg} / \mathrm{l}) \mathrm{e}$ $42 \%$ como de alto risco (> 3mg/l). Houve concordância destes resultados com o método de quimioluminescência em $97 \%$ das dosagens ( $k a p p a=0,96 ; p<0,001$ ). Todas as discordâncias foram de apenas um nível de risco (Figura 4).

\section{Reprodutibilidade do método de quimioluminescência}

As amostras diluídas para avaliação da reprodutibilidade apresentaram medidas de PCR-as entre $0,12 \mathrm{mg} / \mathrm{l} \mathrm{e}$ $0,56 \mathrm{mg} / \mathrm{l}$. Observou-se reprodutibilidade satisfatória do método quimioluminescente, com coeficiente de variabilidade entre duas medidas repetidas de $4,4 \%$.

\section{Discussão}

A análise dos presentes dados evidencia que medidas séricas de PCR-as pelo método quimioluminescente apresentam forte associação linear, valores suficientemente semelhantes e alto nível de concordância na classificação de risco cardiovascular em relação a medidas do método nefelométrico. Além disso, o desempenho do método quimioluminescente nas dosagens repetidas de soros com baixas concentrações de PCR-as mostra que sua precisão obedece à definição de alta sensibilidade ${ }^{(7)}$.

A presença de associação linear entre um novo método e seu padrão de referência, tal como observado em nossa casuística, permite inferir que os resultado das duas

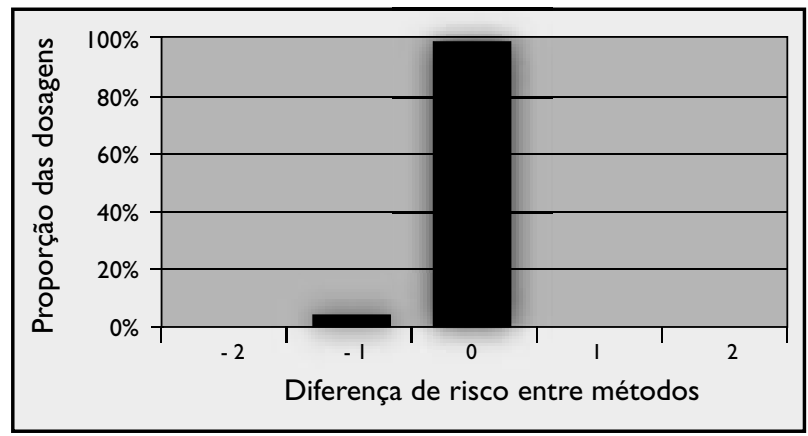

Figura 4 - Gráfico de barras indicando a proporção de amostras em que os métodos concordaram entre si (abscissa $=0$ ) quanto à classificação de risco cardiovascular (baixo, médio ou alto), discordaram em um nível (abscissa = 1 ou - 1) ou discordaram em dois níveis (abscissa = 2 ou - 2) dosagens são influenciados por fenômenos biológicos na mesma proporção. Contudo este dado não assegura a semelhança dos valores absolutos, não garantindo a adequação do novo método para utilizar os mesmos limites de referência daqueles já validados para a prática clínica. Para este propósito, a avaliação da diferença absoluta entre os resultados dos métodos assume maior importância. Em nossa casuística, esta comparação inicialmente demonstra divergência substancial entre os métodos. Por outro lado, há um comportamento diferente entre valores baixos e altos de PCR-as, estando as maiores divergências nos valores de PCR-as $>4 \mathrm{mg} / \mathrm{l}$. A distinção entre indivíduos de baixo, intermediário ou alto risco ocorre na faixa $<4 \mathrm{mg} / \mathrm{l}$, onde encontramos valores semelhantes entre os dois métodos. Por este motivo, quando utilizados pontos de corte epidemiologicamente validados para nefelometria ${ }^{(7)}$, o método quimioluminescente apresenta alto nível de concordância com o primeiro na estratificação do risco cardiovascular. A precisão necessária para que um método de PCR-as seja considerado de alta sensibilidade é definida por um coeficiente de variabilidade $<10 \%$, calculado para concentrações séricas em torno de $0,3 \mathrm{mg} / \mathrm{l}^{(7)}$. Desta forma, de acordo com o presente trabalho, o método quimioluminescente apresentou uma boa precisão.

A nefelometria foi o primeiro método de alta sensibilidade a se tornar disponível para utilização clínica, sendo usado no maior estudo de coorte prospectiva desenhado para avaliar o valor da medida de PCR-as como marcador de risco cardiovascular ${ }^{(8)}$. Pela sua maior casuística, este foi o método mais utilizado na definição dos pontos de corte para classificação de risco cardiovascular. Nos últimos anos, a sensibilidade de outros métodos quantitativos tem sido aprimorada, o que os torna aptos a mensurar baixos valores de PCR-as. Em populações de síndromes coronarianas agudas, nas quais o valor da PCR-as está nitidamente desviado para cima, métodos como turbidimetria ${ }^{(1,6)}$ e quimioluminescência ${ }^{(4)}$ se ajustam mais facilmente. No entanto, para a sua utilização no cenário de prevenção primária, onde os valores de PCR-as são baixos, fazem-se necessárias cuidadosa avaliação da acurácia e precisão de novos métodos. Dois trabalhos prévios realizados por Robert et al. compararam quimioluminescência e nefelometria em indivíduos estáveis, encontrando forte associação linear. O primeiro estudo ${ }^{(11)}$ mostrou divergência significativa entre os dois métodos $(0,36 \pm 0,15$ no terceiro quartil), sugerindo que valores de referência específicos para o método quimioluminescente devem ser definidos por estudos epidemiológicos. Por outro lado, o segundo trabalho ${ }^{(12)}$ mostrou valores semelhantes 
entre os dois métodos (diferença de $0,05 \pm 0,18$ no terceiro quartil) e concordância de $94 \%$ da definição do quartil de PCR-as, utilizando-se os pontos de corte do método nefelométrico. Nossos dados confirmam os achados deste último trabalho quanto à acurácia do método quimioluminescente em relação ao nefelométrico.

A população alvo do presente estudo é a de prevenção primária, sendo assim selecionados soros obtidos na rotina de indivíduos ambulatoriais. Como nossa amostra foi aleatória, critérios clínicos não foram usados na seleção dos participantes. Assim, não podemos garantir que a nossa casuística seja representada por indivíduos sem doença aterosclerótica manifesta. Por outro lado, sendo a amostra menos específica, esta tem maior validade externa para a população geral.

A despeito do valor prognóstico da PCR-as estar estabelecido, a utilização deste marcador na prática clínica tem sido limitada, pois o método de alta sensibilidade não está bem difundido pelos laboratórios. A confirmação de que a dosagem de PCR-as de alta sensibilidade não é uma habilidade restrita ao método nefelométrico oferece alternativas por vezes mais factíveis, contribuindo para a melhor tradução das evidências científicas para a prática clínica. Futuros estudos de coorte prospectiva avaliando o valor preditor destas novas alternativas em relação a eventos cardiovasculares tornarão maior o nível de evidência a favor de novos métodos e definirão pontos de corte específicos. Nesta linha, recente estudo de caso-controle aninhado, envolvendo mais de 6 mil indivíduos, utilizou o método turbidimétrico para avaliar o valor preditor da PCR-as ${ }^{(3)}$.

Em conclusão, o método de quimioluminescência para medida de proteína C-reativa representa uma alternativa ao método nefelométrico quanto à determinação de risco cardiovascular na população geral.

\section{Referências}

I. CORREIA, L. C. et al. Correlation between turbidimetric and nephelometric methods of measuring C-reactive protein in patients with unstable angina or non-ST elevation acute myocardial infarction. Arq Bras Cardiol, v. 81, p. 1332, 2003

2. CYBULSKY, M. I. et al. A major role forVCAM- I, but not ICAMI, in early atherosclerosis. J Clin Invest, v. 107, p. 1255-62, 2001.

3. DANESH, J. et al. C-Reactive protein and other circulating markers of inflammation in the prediction of coronary heart disease. N Engl I Med, v. 350, p. I 387-97, 2004.

4. JAMES, S. K. et al. Troponin and C-reactive protein have different relations to subsequent mortality and myocardial infarction after acute coronary syndrome: a GUSTO-IV substudy. JAm Coll Cardiol, v. 4I, p. 916-24, 2003

5. KULLER, L. H. et al. Relation of C-reactive protein and coronary heart disease in the MRFIT nested case-control study. Multiple Risk Factor Intervention Trial. Am J Epidemiol, v. I44, p. 537-47, 1996.

6. MUELLER, C. et al. Inflammation and long-term mortality after non-st elevation acute coronary syndrome treated with a very early invasive strategy in 1,042 consecutive patients. Circulation, v. 105, p. I4|2-5, 2002.

7. PEARSON, T. A. et al. Markers of inflammation and cardiovascular disease: application to clinical and public health practice: a Statement for Healthcare Professionals From the Centers for Disease Control and Prevention and the American Heart Association. Circulation, v. 107, p. 499-5। I, 2003.

8. RIDKER, P. M. et al. Comparison of C-reactive protein and lowdensity lipoprotein cholesterol levels in the prediction of first cardiovascular events. N Engl J Med, v. 347, p. I557-65, 2002.
9. RIDKER, P. M. et al. Inflammation, aspirin, and the risk of cardiovascular disease in apparently healthy men. N Engl J Med, v. 336, p. 973-9, 1997.

10. RIFAI, N.; TRACY, R. P.; RIDKER, P. M. Clinical efficacy of an automated high-sensitivity $\mathrm{C}$-reactive protein assay. Clin Chem, v. 45, p. 2136-4I, 1999.

I I. ROBERTS, W. L. et al. Evaluation of four automated highsensitivity C-reactive protein methods: implications for clinical and epidemiological applications. Clin Chem, v. 46, p. $46 \mid-8,2000$.

12. ROBERTS, W. L. et al. Evaluation of nine automated highsensitivity c-reactive protein methods: implications for clinical and epidemiological applications. Part 2. Clin Chem, v. 47, p. $4|8-25,200|$.

13. SHAH, P.K. et al. Human monocyte-derived macrophages induce collagen breakdown in fibrous caps of atherosclerotic plaques. Potential role of matrix-degrading metalloproteinases and implications for plaque rupture. Circulation, v. 92, p. 1565-9, 1995.

\section{Endereço para correspondência}

José Carlos Carneiro Lima Avenida Paulo VI 1.920 - Pituba CEP 41830-000 - Salvador-BA Tel.: (71) 359-3300 e-mail: jclima@laboratoriolpc.com.br 